\title{
High Risk of Failure With Bimodular Femoral Components in THA
}

\author{
Aidin Eslam Pour MD, Robert Borden BS, Takayuki Murayama MD, \\ Mary Groll-Brown BS, J. David Blaha MD
}

Received: 12 February 2015/Accepted: 24 August 2015/Published online: 1 September 2015

(C) The Association of Bone and Joint Surgeons (B) 2015

\begin{abstract}
Background The bimodular femoral neck implant (modularity in the neck section and prosthetic head) offers several implant advantages to the surgeon performing THAs, however, there have been reports of failure of bimodular femoral implants involving neck fractures or adverse tissue reaction to metal debris. We aimed to assess the results of the bimodular implants used in the THAs we performed.

Questions/purposes We asked: (1) What is the survivorship of the PROFEMUR ${ }^{\circledR}$ bimodular femoral neck stems? (2) What are the modes of failure of this bimodular femoral neck implant? (3) What are the major risk factors for the major modes of failure of this device?
\end{abstract}

Each author certifies that he or she, or a member of his or her immediate family, has no funding or commercial associations (eg, consultancies, stock ownership, equity interest, patent/licensing arrangements, etc) that might pose a conflict of interest in connection with the submitted article. All authors have read and agreed with the contents of the manuscript.

All ICMJE Conflict of Interest Forms for authors and Clinical Orthopaedics and Related Research ${ }^{\circledR}$ editors and board members are on file with the publication and can be viewed on request.

Clinical Orthopaedics and Related Research ${ }^{\circledR}$ neither advocates nor endorses the use of any treatment, drug, or device. Readers are encouraged to always seek additional information, including FDA approval status, of any drug or device before clinical use.

Each author certifies that his or her institution has approved the human protocol for this investigation and that all investigations were conducted in conformity with ethical principles of research, and that informed consent was obtained.

A. E. Pour ( $\varangle)$, R. Borden, T. Murayama, M. Groll-Brown, J. D. Blaha

Department of Orthopaedic Surgery, University of Michigan, 2912 Taubman Center, 1500 E. Medical Center Drive,

SPC 5328, Ann Arbor, MI 48103, USA

e-mail: aeslampo@med.umich.edu
Methods Between 2003 and 2009, we used one family of bimodular femoral neck stems for all primary THAs (PROFEMUR ${ }^{\circledR} \mathrm{Z}$ and PROFEMUR ${ }^{\circledR}$ E). During this period, 277 THAs (in 242 patients) were performed with these implants. One hundred seventy were done with the bimodular PROFEMUR ${ }^{\circledR} \mathrm{E}$ (all are accounted for here), and when that implant was suspected of having a high risk of failure, the bimodular PROFEMUR ${ }^{\circledR} \mathrm{Z}$ was used instead. One hundred seven THAs were performed using this implant (all are accounted for in this study). All bearing combinations, including metal-on-metal, metal-on-polyethylene, and ceramic-on-ceramic, are included here. Data for the cohort included patient demographics, BMI, implant dimensions, type of articular surface, length of followup, and C-reactive protein serum level. We assessed survivorship of the two stems using Kaplan-Meier curves and determined the frequency of the different modes of stem failure. For each of the major modes of failure, we performed binary logistic regression to identify associated risk factors.

Results Survivorship of the stems, using aseptic revision as the endpoint, was $85 \%$ for the patients with the PROFEMUR ${ }^{\circledR}$ E stems with a mean followup of 50 months (range, 1-125 months) and $85 \%$ for the PROFEMUR ${ }^{\circledR} \mathrm{Z}$ with a mean followup of 50 months (range, $1-125$ months)(95\% CI, 74-87 months). The most common modes of failure were loosening (9\% for the PROFEMUR ${ }^{\circledR} \mathrm{E}$ ), neck fracture (6\% for the PROFEMUR ${ }^{\circledR} \mathrm{Z}$ and $0.6 \%$ for the PROFEMUR ${ }^{\circledR} E$ ), metallosis $(1 \%)$, and periprosthetic fracture (1\%). Only the bimodular PROFEMUR ${ }^{\circledR}$ E was associated with femoral stem loosening (odds ratio [OR] $=1.1 ; 95 \% \mathrm{CI}, 1.04-1.140 ; \mathrm{p}$ $=0.032)$. Larger head $(\mathrm{OR}=3.2 ; 95 \% \mathrm{CI}, 0.7-14 ; \mathrm{p}=0.096)$, BMI $(\mathrm{OR}=1.19 ; 95 \% \mathrm{CI}, 1-1.4 ; \mathrm{p}=0.038)$ and total offset $(\mathrm{OR}=1.83 ; 95 \% \mathrm{CI}, 1.13-2.9 ; \mathrm{p}=0.039)$ were associated with neck fracture.

Conclusion Bimodular neck junctions may be potentiated by long neck lengths, greater offset, and larger head 
diameters. These factors may contribute to bimodular neck failure by creating a larger moment about the neck's insertion in the stem. The PROFEMUR ${ }^{\circledR} \mathrm{E}$ implant is associated with high periprosthetic loosening. Based on our experience we cannot recommend the use of bimodular femoral neck implants.

Level of Evidence Level III, therapeutic study.

\section{Introduction}

Hip offset and length are known to affect the forces around the joint, stability of the hip, and even longevity of the bearing surface $[1,6,20]$. A decrease or increase greater than $5 \mathrm{~mm}$ in offset can negatively affect the wear of the contact surfaces by increasing the joint reaction forces [24, 25]. Matching implant size, length, and offset to the patient's needs during THA therefore is believed to be important for best function and durability. Bimodular femoral neck components were introduced to allow surgeons more options in neck-shaft angle, neck version, and length, with the hope of more consistently achieving a more "ideal" position of the components [19, 22].

Failures of bimodular necks have been reported, including bimodular neck fracture and corrosion with pseudotumor and periprosthetic loosening $[2,7,15,27,28,30,31]$. Mechanical analyses have suggested that corrosion-assisted fatigue is an important mechanism of failure, and design choices in metallurgy, offset, caput-column diaphysis angle, and mechanical stresses of physical activity are factors contributing to corrosion $[7,11,16,33]$. As with any new technology, the risk-benefit analysis must show that the advantages of modularity outweigh the risks. However, in terms of design and materials, not all modular necks are the same. Our study concerns a bimodular neck constructed of TiAlV alloy for the neck and the stem. Although at the time of writing this article, a bimodular neck-stem system has been recalled from the market, the system reported in this article has not been recalled. The data regarding followup of this group of patients can help guide recommendations for followup and the need for revision.

We asked: (1) What is the survivorship of bimodular PROFEMUR $^{\circledR}$ femoral stems? (2) What are the modes of failure of this bimodular femoral neck implant? (3) What are the major risk factors for the major modes of failure of this device?

\section{Methods and Materials}

Institutional review board approval and patient consent were obtained for this single-surgeon (JDB) retrospective study performed at a large academic hospital. Between 2003 and 2009, the senior surgeon (JDB) used one family of bimodular neck stems for all of his primary THAs (PROFEMUR ${ }^{\circledR} \mathrm{Z}$ and PROFEMUR ${ }^{\circledR}$ E; Wright Medical Technology, [MicroPort Orthopaedics], Arlington, TN, USA). During this period, he performed 277 THAs in 242 patients with these implants. One hundred seventy THAs were done with the PROFEMUR ${ }^{\circledR}$ E, and when that implant was suspected of having a high risk of failure owing to periprosthetic loosening, the surgeon switched to the PROFEMUR ${ }^{\circledR} \mathrm{Z}$ and 107 of these implants were used in. All bearing combinations, including metal-on-metal, metal-on-polyethylene, and ceramic-on-ceramic, are included here (Table 1).

We present the survivorship of the bimodular PROFEMUR $^{\circledR}$ E, a titanium alloy surface-roughened stem, and the bimodular PROFEMUR ${ }^{\circledR}$ Z, a titanium alloy, surfaceroughened, and proximally plasma-sprayed stem with the endpoint of aseptic revision. Neither stem has a surface with interconnecting porosity. The neck is fabricated from titanium alloy and has two lengths (short and long), two options for neck-shaft angle ( $8^{\circ}$ varus and $8^{\circ}$ valgus), and two options for femoral-neck version $\left(8^{\circ}\right.$ anteverted and $8^{\circ}$ retroverted). The senior surgeon (JDB) chose the bimodular PROFEMUR ${ }^{\circledR}$ E stem with the bimodular neck because of long-term experience with the CLS ${ }^{\circledR}$ prosthesis (Zimmer Inc, Warsaw, IN, USA), which has a similar but not identical shape. Because of a substantial rate of loosening by subsidence with the bimodular PROFEMUR ${ }^{\circledR} E$, in 2006 the bimodular PROFEMUR ${ }^{\circledR} \mathrm{Z}$ stem was chosen for use. Because of reports of fracture of the bimodular neck, use of PROFEMUR ${ }^{\circledR}$ stems that accommodated the bimodular neck was abandoned [5, 7, 13, 16, 28, 32, 33].

Table 1. Implants used

\begin{tabular}{lc}
\hline Implant & Number used \\
\hline Stem model* $^{*}$ & 170 \\
PROFEMUR $^{\circledR}$ E & 107 \\
PROFEMUR $^{\circledR} Z$ & \\
Neck types $^{\circledR}$ & 230 \\
Short & 47 \\
Long & 147 \\
No version & 124 \\
Retroversion & 6 \\
Anteversion & \\
Shell model & 161 \\
Conserve & \\
Lineage $^{\circledR}$ & 74 \\
Dynasty & \\
SUPER-FIX $^{\circledR}$ & 25 \\
Bearing surface & 17 \\
Metal-on-metal & \\
Ceramic-on-ceramic & 180 \\
Metal-on-polyethylene & 62 \\
\hline
\end{tabular}

* All from Wright Medical Technology, Arlington, TN, USA. 
The type of surgery (primary or revision THA), bimodular neck, and articulation (metal-on-metal, ceramic on metal, metal-metal, ceramic-ceramic, metal-polyethylene, or ceramic-polyethylene) were determined from the database and operative logs and records and confirmed with radiographic images. Initially, the articular surface chosen was metal-on-polyethylene, ceramic-on-polyethylene, ceramicon-ceramic, or small-head metal-on-metal. When large-head metal-on-metal surfaces became available, nearly all arthroplasties were done using that articulation. All primary arthroplasties were performed through an anterolateral approach with the patient in the semilateral decubitus position, and revision surgeries were performed through the approach of the original arthroplasty.

Postoperative followups occurred at 2 weeks, 6 weeks, 6 months, 1 year, 5 years, and at 5 -year intervals thereafter per a routine protocol. Owing to reports of complications associated with bimodular neck implants, patients with these implants had been contacted by letter and followup telephone call and invited to return for more frequent followups. If there was no response to two letters and two telephone calls, patients who could not be located were classified as lost to followup.

Two hundred forty-two patients (277 hips) with bimodular femoral neck components who did not have periprosthetic infection or revision for loosening or malposition of the acetabular implant, were included in our survivorship analysis (Table 2). Our study endpoint was aseptic revision of the femoral stem. Eleven hips were revised for periprosthetic infection and were not included. Four hips were revised for loosening or malposition of acetabular implant and not mainly for stem failure. This left 262 hips (102 hips with the PROFEMUR ${ }^{\circledR} \mathrm{Z}$ and 160 hips with the PROFEMUR ${ }^{\circledR}$ E implant). Despite multiple attempts to reach the patients via telephone and mail to invite them for clinical assessment, the actual number of patients followed more than 5 years was disappointing. The length of followup was less than 1 year in 49 patients (51 hips, 18\%), 1 to 2 years for 25 patients ( 28 hips, 10\%), 2 to 5 years for 61 patients (72 hips, 26\%), and 5 to 10 years for 107 patients (123 hips, 44\%). For patients who returned for followup, the mean followup was 4.2 years (range, $0.1-10.4$ years).

During the study period, revision THA was offered to patients with these implants who were symptomatic, when the stem was observed on plain radiographs to be loose, when a diagnosis of infection could be made, or when we found a bimodular neck fracture. If the radiographs were not conclusive, metal artifact reduction sequence MRI was obtained to assess the patient for adverse tissue reaction to metal debris. If a pseudotumor was observed on MR images, it was discussed with the patient and revision surgery was offered. For patients who were asymptomatic, we followed their metal ion levels annually.
Table 2. Demographics and preoperative diagnoses

\begin{tabular}{ll}
\hline Factor & Measure \\
\hline Hips & 277 \\
Patients & 242 \\
Sex & \\
Men & 112 \\
Women & 130 \\
Average BMI at surgery (kg/m $\left.{ }^{2} \pm \mathrm{SD}\right)$ & $30.2 \pm 6.3$ \\
Average age at surgery, years & $57.4 \pm 14.1$ \\
Average length of followup, years & $4.16 \pm 2.9$ \\
Deceased & 18 \\
Preoperative diagnoses & \\
Osteoarthritis & 236 \\
Avascular necrosis & 22 \\
Rheumatoid arthritis & 10 \\
Avascular necrosis and osteoarthritis & 9 \\
\hline
\end{tabular}

For patients who returned for followups, history and physical examinations were conducted to note any symptoms referable to the hip in question, and particularly, for any change in symptoms and any evidence of weakness, palpable mass, or irritability of the hip. Plain radiographs were evaluated for loosening and osteolysis. Metal ion concentrations were determined in patients' blood serum, including cobalt, chromium, titanium, and nickel. C-reactive protein levels and sedimentation rates were measured in patients who were symptomatic. If a patient had any change in symptoms around the hip or if metal ion levels were of concern, MRI using metal artifact reduction sequence was performed to look for evidence of reaction to the components. There was no specific protocol for evaluation of these tests and the levels that were considered concerning have changed, as recommendations regarding serum metal ion concentrations changed during the time of these evaluations.

\section{Statistical Analysis}

First, we assessed survivorship of the bimodular PROFEMUR ${ }^{\circledR}$ E and Zimplants free of aseptic revision using KaplanMeier survival analysis. The patients who had aseptic revision unrelated to the bimodular femoral stem were excluded from this analysis. We considered the last clinic visit for patients who did not have revision surgery for this analysis. This left 160 bimodular PROFEMUR ${ }^{\circledR}$ E stems (of 170) and 102 bimodular PROFEMUR ${ }^{\circledR} \mathrm{Z}$ stems (of 107) (Fig. 1). We then performed frequency analysis for the different modes of failure. Modes of failure were defined as periprosthetic loosening, periprosthetic fracture, bimodular neck fracture, adverse local tissue response to metal debris, and intraarticular gas.

Finally, we attempted to identify risk factors for the major modes of failure. All possible risk factors for stem 


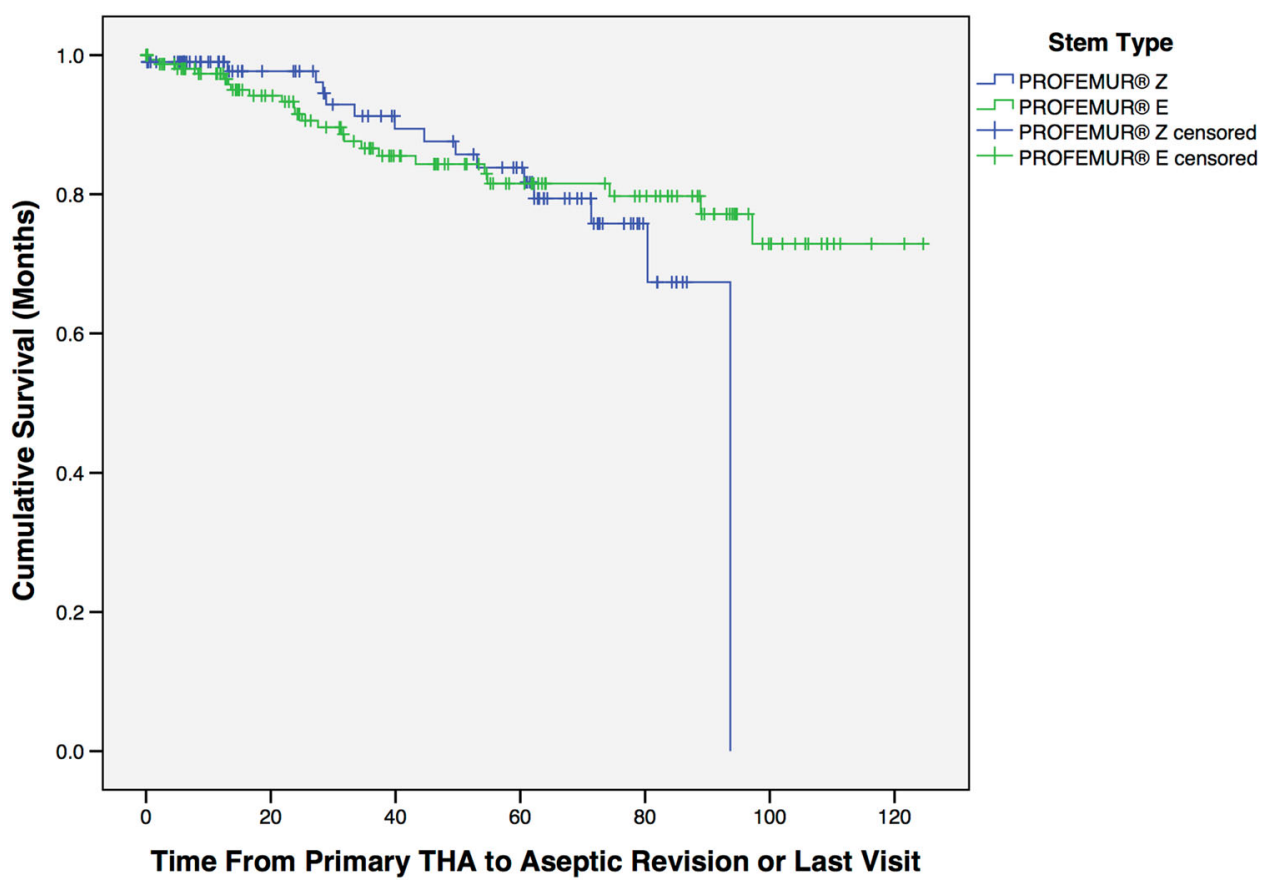

Fig. 1 The Kaplan Meyer survivorship graph shows aseptic revision of the bimodular PROFEMUR ${ }^{\circledR}$ E and $\mathrm{Z}$ femoral stems (time is presented in months from the primary THA).

failure or bimodular neck fracture were tested in univariate regression analysis. Factors that correlated positively were included in a logistic regression model.

Normal distribution of the data was checked using the Shapiro-Wilk normality test for each series of measurements. For data with normal distribution, paired t-tests and an independent sample t-test were used for analysis. For data without normal distribution, related samples, Wilcoxon rank sum test, and the independent sample Mann-Whitney test were used for the analysis. Binary logistic regression was performed, which provided odds ratios $(\mathrm{OR})$ for the variables and further supported their significance. All data were analyzed using MedCalc ${ }^{\mathbb{R}}$ software (MedCalc ${ }^{\mathbb{R}}$ Software, Ostend, Belgium), version 11.3, and SPSS ${ }^{\circledR}$ software (Version 21.0; IBM Corporation, New York, NY, USA).

\section{Results}

\section{Survivorship}

We performed the survivorship analysis considering the last date of patients' clinical assessment in the clinic. The analysis with aseptic revision of the femoral stem as the end point for failure showed a survival rate of $85 \%$, with a mean followup of 50 months (range, 1-125 months) (95\% CI, 96-111 months) for the PROFEMUR ${ }^{\circledR}$ E femoral stem and $85 \%$ (95\% CI, 74-87 months) for the PROFEMUR ${ }^{\circledR} \mathrm{Z}$ stem (Fig. 1$)(\mathrm{p}=0.587)$. The log rank test did not show any difference in the survival rates of the two stems $(\mathrm{p}=0.637)$.

\section{Modes of Failure}

The overall proportion of patients with aseptic failure of the bimodular femoral stem only was $15 \%$ (36 of 242 patients, 38 of 262 hips; 95\% CI, 10\%-19\%), with the most common mode of failure being aseptic femoral stem loosening, which was observed in 9\% of hips with the bimodular PROFEMUR ${ }^{\circledR}$ E stem (15 of 146 patients, 15 of 160 hips; 95\% CI, $5 \%-14 \%$ ). Other modes of failure were neck fracture (6\% of bimodular PROFEMUR ${ }^{\circledR} \mathrm{Z}$ stems; six of 96 patients, six of 102 hips; 95\% CI, 1.3\%-10.4\%; and $0.6 \%$ of bimodular PROFEMUR ${ }^{\circledR}$ E stems, one of 146 patients, one of 160 hips; 95\% CI, $0.5 \%-2 \%$ ) periprosthetic fracture $2 \%$; (three of 242 patients, four of $262 \mathrm{hips} ; 95 \% \mathrm{CI}, 0.5 \%-3 \%$ ), and adverse local tissue response to metal debris 2\%; (three of 242 patients, four of 262 hips; 95\% CI, 0.5\%-3\%) (Table 3).

Factors Associated With the Most Common Modes of Failure

\section{Periprosthetic Loosening}

Only stem type (PROFEMUR ${ }^{\circledR}$ E) was associated with femoral stem loosening $(\mathrm{OR}=1.1 ; 95 \% \mathrm{CI}, 1.04-1.14, \mathrm{p}=$ 0.032 ). In univariate and binary logistic regression analyses for the hips with the PROFEMUR ${ }^{\circledR} \mathrm{E}$ implant, the only variable that was associated with loosening was male sex $(\mathrm{OR}=3.6$; 95\% CI, 1.2-11.7, $\mathrm{p}=0.084)$. Other variables 
Table 3. Data regarding implant failure

\begin{tabular}{ll}
\hline Implant failure data & Number (\%) \\
\hline Hips requiring revision surgery & $54 / 277(19)$ \\
Infection & $11(4)$ \\
Acetabular/linear revision & $4(1)$ \\
Aseptic revision of femoral stems & $39 / 262(15)$ \\
Bimodular PROFEMUR ${ }^{\circledR}$ E & $162 / 262$ \\
Femoral stem loosening & $15(9)$ \\
Implant neck fracture & $1(1)$ \\
Periprosthetic fracture & $3(2)$ \\
Adverse local tissue response & $1(1)$ \\
Bimodular PROFEMUR ${ }^{\circledR} \mathrm{Z}$ & $102 / 262$ \\
Femoral stem loosening & $0(0)$ \\
Implant neck fracture & $6(6)$ \\
Periprosthetic fracture & $1(1)$ \\
Adverse local tissue response & $3(3)$ \\
\hline
\end{tabular}

were BMI $(p=0.645)$, neck length $(p=0.874)$, neck-shaft angle $(\mathrm{p}=0.820)$, neck version $(\mathrm{p}=0.803)$, bearing surface type $(0.816)$, or prosthetic head size $(\mathrm{p}=0.902)$.

\section{Bimodular Neck Fracture}

Seven modular femoral neck implants fractured. The rate of femoral neck fracture was greater among PROFEMUR ${ }^{\circledR}$ $\mathrm{Z}$ stems (six of 107 hips; 5.6\%) than PROFEMUR ${ }^{\circledR}$ E stems (one of $170 ; 0.6 \% ; \mathrm{p}<0.001$ ) (Table 3 ). This rate also was greater among long femoral necks compared with short necks $(15 \%$ versus $0.0 \% ; \mathrm{p}<0.001)$. The rate was not statistically different $(\mathrm{p}=0.548)$ between varus and valgus necks. Using binary logistic regression, optimum modeling regarding likelihood of neck fracture was achieved by including BMI, total offset, and head diameter. Positive correlations for neck fracture were found for head diameter, total offset, and BMI $(\mathrm{p}<0.1)$. Using binary logistic regression, optimum modeling regarding likelihood of neck fracture was achieved by including BMI, total offset, and head diameter. This model indicates that a one-unit increase in BMI increased the probability of fracturing the implant by a multiplicative factor of 1.19 (95\% CI, $0.9-1.44 ; \mathrm{p}=0.038$ ). The head diameters range from 28 to $56 \mathrm{~mm}$ for these implants. Each 4-mm increase in head diameter (from 28 to $32 \mathrm{~mm}, 32$ to $36 \mathrm{~mm}$, and so on) increased the chance of neck fracture by a multiplicative factor of 3.21 (95\% CI, 1.01-5.69; p = 0.096). Each 1-mm increase in total offset was associated with a 1.83 times increased likelihood of neck fracture (95\% CI, 1.13-2.9; p $=0.039$ ). Although all necks that fractured were long, the correlation with neck length was not strong enough to achieve significance in this model $(\mathrm{p}=0.612)$.
Table 4. Overall serum metal levels of the patients

\begin{tabular}{lll}
\hline Serum metal & Range $(\mathrm{ng} / \mathrm{mL})$ & Average \pm SD $(\mathrm{ng} / \mathrm{mL})$ \\
\hline $\mathrm{Co}$ & $0-41$ & $5.23 \pm 6.9$ \\
$\mathrm{Cr}$ & $0-23$ & $3.16 \pm 3.8$ \\
$\mathrm{Ti}$ & $0-81$ & $4.81 \pm 9.6$ \\
$\mathrm{Ni}$ & $0-1.4$ & $0.58 \pm 0.26$ \\
\hline
\end{tabular}

\section{Periprosthetic Fracture}

Periprosthetic fracture occurred in four implants (1.4\%). There were no differences in the numbers of fractures between the PROFEMUR ${ }^{\circledR}$ E compared with PROFEMUR ${ }^{\circledR} \mathrm{Z}$ stems, long versus short necks, or varus versus nonvarus necks ( $\mathrm{p}=0.568,0.374$, and 0.651 , respectively). None of the variables was found to correlate with this complication in univariate and logistic regression analyses.

\section{Adverse Local Tissue Response to Metal Debris}

Four patients had an adverse local tissue response to metal debris that required revision surgery. There were no statistical differences between the PROFEMUR ${ }^{\circledR}$ E compared with PROFEMUR ${ }^{\circledR} \mathrm{Z}$ stems $(\mathrm{p}=0.130)$, long compared with short necks $(p=0.367)$, or varus compared with nonvarus necks $(p=0.650)$ for being a risk factor associated with tissue response to metal debris. Blood serum levels for metal concentrations were obtained for 96 patients (39.7\% of all participants) (Table 4); the remaining patients were lost to followup or unwilling to return owing to lack of symptoms. Three patients had high Co serum concentrations $(41,40$, and $40 \mathrm{ng} / \mathrm{mL}$ ); these three patients all had implants with a metal-on-metal bearing surface. One patient had a Ti level of $81 \mathrm{ng} / \mathrm{mL}$, which decreased to $41 \mathrm{ng} / \mathrm{mL}$ approximately 1 year later. The patient also had an implant with a metal-on-metal bearing surface.

Two tailed t-tests revealed that Ti levels were greater in patients with bilateral hip revisions $(4.27 \mathrm{ng} / \mathrm{mL})$ than in patients with unilateral revisions $(1.55 \mathrm{ng} / \mathrm{mL} ; \mathrm{p}=0.023)$; $\mathrm{Co}, \mathrm{Cr}$, and $\mathrm{Ni}$ levels were not greater in patients with bilateral hip revisions. Considering all hips requiring aseptic revision surgery for any reason $(n=43)$, the mean $\mathrm{Cr}$ and $\mathrm{Ti}$ serum levels were greater in patients who had aseptic revision surgery $(p=0.003$ and $p=0.023$, respectively), but not greater for mean $\mathrm{CO}$ or $\mathrm{Ni}$ levels (Table 5).

Three surgeries, all using the PROFEMUR ${ }^{\circledR} \mathrm{Z}$ stem and Conserve ${ }^{\circledR}$ cup, required revision for gas in the joint. There was one instance of hydrogen pneumarthrosis observed on radiographs; gas was identified surrounding the neck of the 
Table 5. Serum metal levels for patients ${ }^{\dagger}$ who did and did not undergo aseptic revision surgery

\begin{tabular}{lllll}
\hline Status & Cobalt & Chromium & Titanium & Nickel \\
\hline Aseptic revision performed & $3.7 \mathrm{ng} / \mathrm{mL}$ & $3.5 \mathrm{ng} / \mathrm{mL}^{*}$ & $3.6 \mathrm{ng} / \mathrm{mL}^{*}$ & $0.56 \mathrm{ng} / \mathrm{mL}^{*}$ \\
No aseptic revision performed & $2.2 \mathrm{ng} / \mathrm{mL}$ & $1.5 \mathrm{ng} / \mathrm{mL}^{*}$ & $1.5 \mathrm{ng} / \mathrm{mL}^{*}$ & $0.51 \mathrm{ng} / \mathrm{mL}^{*}$ \\
\hline
\end{tabular}

Metal laboratory data unavailable for $60.3 \%$ of patients; ${ }^{*} \mathrm{p}<0.05$.

prosthesis. The patient did not require revision surgery, as the gas and pain symptoms resolved. The patient's serum metal levels at the time of his symptoms were: cobalt, 3.2 $\mathrm{ng} / \mathrm{mL}$; chromium, $2.8 \mathrm{ng} / \mathrm{mL}$; titanium, $9.0 \mathrm{ng} / \mathrm{mL}$; and nickel, $1.4 \mathrm{ng} / \mathrm{mL}$.

\section{Other Causes for Revision}

There were 11 occurrences of infection (4\%; of 277 hips): one patient underwent revision surgery for a limb-length discrepancy $(0.4 \%$; of $277 \mathrm{hips})$; the ceramic liner was revised in one patient for fracture $(0.4 \%$; of 277 hips); and one patient required revision surgery for noise among the patients who had a ceramic-on-ceramic bearing surface implant $(0.4 \%$; of $277 \mathrm{hips})$. One patient $(0.4 \%$; of 277 hips) underwent revision surgery for hip instability. These patients were not included in the survivorship analysis.

\section{Discussion}

Bimodular femoral neck components were introduced to help match implant size, limb length, and femoral headneck offset to those of the patient, with the goal of improving function and perhaps implant durability. However, failures of these components have been reported $[2,7$, $15,27,28,30,31]$; thus long-term survivorship of and complications associated with bimodular femoral neck components must be assessed to determine if the benefits outweigh the risks of failure. In our retrospective study, we evaluated a series of bimodular femoral neck implants used for primary THA to determine survivorship, main causes of failure, and the risk factors associated with them. We found that failure of bimodular neck junctions may be potentiated by long neck lengths, greater offset, and larger head diameters. It is suspected that these factors contribute to bimodular neck failure by creating a larger moment about the neck's insertion in the stem.

The most important weakness of our study was the high percentage of patients who were lost to followup. Despite multiple attempts to contact them, we were unable to contact some patients and some declined to return for followup owing to distance or lack of symptoms. For patients who lived too far away for direct followup, we recommended establishing care with a local orthopaedic surgeon. Overall, the length of followup (242 patients; 277 hips) was less than 1 year for 49 patients $(20.3 \%$ of patients; 51 hips, $18.4 \%$ ), 1 to 2 years for 25 patients (10.4\% of patients; 28 hips, $10.1 \%), 2$ to 5 years in 61 patients (25.2\% of patients; 72 hips, 26\%), and 5 to 10 years in 107 patients ( $44.2 \%$ of patients; 123 hips, $44.4 \%$ ). The average followup for patients who returned was 4.2 years (range, 0.1-10.4 years). With more than $1 / 2$ of the patients unaccounted for at 5 years, and knowing that patients who are lost to followup are more likely to have had complications or revisions, we must consider our findings a best-case analysis with this implant. The actual risk of reoperation may be even greater than the $19.5 \%$ that we observed here.

We found unacceptable survivorship of the bimodular neck PROFEMUR ${ }^{\circledR} \mathrm{E}$ and $\mathrm{Z}$ stems. In the Australian Orthopaedic Association National Joint Replacement Registry, the 1-, 3-, and 10-year revision rates for procedures using the PROFEMUR ${ }^{\circledR} \mathrm{Z}$ stem have been reported as $6 \%$, $10.4 \%$, and $10.9 \%$ (hazard ratio $=2.49 ; \mathrm{p}<0.001$ ) [3]. These are high failure rates compared with other femoral stems currently used for THA. These failure rates are slightly lower than those found in our study. To our knowledge, there are no reports on the bimodular neck PROFEMUR ${ }^{\mathbb{R}}$ E stems in the Australian Orthopaedic Association National Joint Replacement Registry, nor could we find any reports regarding the survivorship of the bimodular PROFEMUR ${ }^{\circledR}$ $E$ and $Z$ stems in the Norwegian and Swedish joint registries. There are more than 100 reports of failure for PROFEMUR ${ }^{\circledR}$ stems in the FDA database [29]. As of June 15, 2015, there were 286 event reports for the PROFEMUR ${ }^{\circledR} \mathrm{Z}$ implant and eight for the PROFEMUR ${ }^{\circledR} E$ in the FDA database. The reports for the PROFEMUR ${ }^{\circledR} \mathrm{Z}$ were for bimodular neck fracture (33 of 286), loosening and subsidence (39 of 286), periprosthetic fracture (four of 286), and corrosion or adverse local tissue response (210 of 286). For the PROFEMUR $^{\circledR}$ E stem, the event reports included loosening (two of eight), bimodular neck fracture (five of eight), and periprosthetic fracture (one of eight). We do not know the rate of use of the PROFEMUR ${ }^{\circledR} \mathrm{E}$ and $\mathrm{Z}$ stems in the United States, therefore we cannot provide the prevalence of these events in this country.

The most common mode of failure was loosening of the bimodular PROFEMUR ${ }^{\circledR}$ E implant. Stem subsidence is 


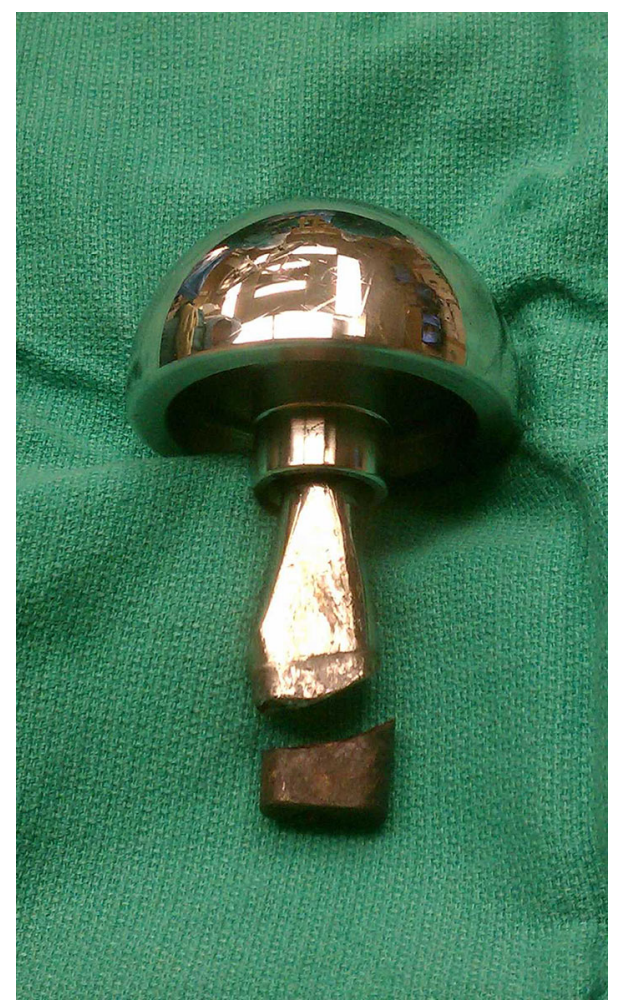

Fig. 2 A corroded, long varus modular neck with fracture is shown. The broken fragment was removed from the stem to allow attachment of an extraction device to remove the stem.

one of the signs of stem loosening. Georgiou et al. [14] assessed the subsidence in bimodular PROFEMUR ${ }^{\circledR}$ E implants in 125 hips radiographically at 2 years followup. All patients had a metal-on-metal bearing surface with a head diameter larger than $36 \mathrm{~mm}$. They reported mean stem subsidence of 0.9 (range, $0-6.7 \mathrm{~mm}$ ) at 2 years and four hips had subsidence greater than $2.4 \mathrm{~mm}$. They found that neck type and head diameter did not affect the rate of the subsidence of the stem [14]. Enoksen et al. [12] studied the micromotion of the PROFEMUR ${ }^{\mathbb{R}}$ GLADIATOR ${ }^{\circledR}$ stem. This stem is similar in design to the PROFEMUR ${ }^{\circledR} \mathrm{Z}$ and it is hydroxyapatite coated. In their cadaveric study, the authors found larger joint forces with shorter and retroverted necks. The lateral translation and varus rotation of the stem were greater in varus necks ( $43 \%-65 \%$ greater). They found that stems with varus retroverted necks had more micromotion compared with other neck types [12]. In another study, Doehring et al. [8] found an increase in micromotion with the use of long bimodular necks owing to greater torsional moment and bending forces. We did not find any correlation between implant loosening and implant neck geometry. We also did not find any correlation between loosening of the stem and neck-head geometry. The only factor that affected loosening was the type of the stem
(PROFEMUR ${ }^{\circledR}$ E versus Z) and male sex among patients with the PROFEMUR ${ }^{\circledR}$ E stem.

The other method of failure in our study was bimodular neck fracture in approximately $5.6 \%$ of the PROFEMUR ${ }^{\circledR}$ $\mathrm{Z}$ stems (six of 107) and $0.6 \%$ of PROFEMUR ${ }^{\circledR}$ E stems (one of 170). There are several case reports regarding bimodular neck fracture of PROFEMUR ${ }^{\circledR}$ femoral stems $[7,21,26]$. Our data also suggest that long neck lengths, greater offset, and larger head diameters may potentiate failure of bimodular neck junctions. We suspect that these factors contribute to bimodular neck failure by creating a larger moment arm about the neck's insertion in the stem. Fracture of the bimodular neck also was reported by Dangles and Altstetter [7]. Corrosion-assisted fatigue has been suggested as the mechanism of failure (Fig. 2). Micromotion at the neck-stem junction results in abrasion and fretting corrosion [17, 18]. Chemomechanical stress is reported to be higher in titanium modular necks compared with cobalt-chromium bimodular necks. This also is true in femoral stems used for primary THA compared with stems used in revisions owing to the longer and larger anchorage cones of revision stems [7, 9, 11, 16, 33].

In our study, the failure rates of PROFEMUR ${ }^{\circledR} \mathrm{Z}$ and PROFEMUR ${ }^{\circledR}$ E prostheses with bimodular necks are unacceptably high. Despite some reports of long-term success with these type of stems $[4,10,22,23]$, our experience led us to abandon use of these bimodular neck stems. The rate of aseptic periprosthetic loosening of the PROFEMUR ${ }^{\circledR}$ E implant was unacceptably high despite lack of a $100 \%$ followup rate and rather short followup time. Although the bimodular neck allowed intraoperative adjustment of head position relative to the shaft, $85 \%$ of the arthroplasties used the same short, varus, retroverted neck. This same position could have been achieved with a nonmodular neck and our experience with the nonmodular neck PROFEMUR ${ }^{\circledR} \mathrm{Z}$ stem has been satisfactory. Therefore we believe that the bimodular neck is unnecessary for routine use and its potential risks outweigh any benefit to its use. We advise caution in choosing the PROFEMUR ${ }^{\circledR}$ E stem owing to its high periprosthetic loosening rate, and for using bimodular neck implants as the frequency of problems with them remains unknown. These data may help identify a set of patient dimensions that contraindicate the use of bimodular neck junctions.

Acknowledgment We thank Christopher B. Robbins, $\mathrm{PhD}$ (Department of Orthopaedic Surgery, University of Michigan) for supplying statistics for our study.

\section{References}

1. Asayama I, Chamnongkich S, Simpson KJ, Kinsey TL, Mahoney OM. Reconstructed hip joint position and abductor muscle 
strength after total hip arthroplasty. J Arthroplasty. 2005;20:414420.

2. Australian Orthopaedic Association National Joint Replacement Registry. Annual Report 2012. Available at: https://aoanjrr.dmac. adelaide.edu.au/en/annual-reports-2012. Accessed June 11, 2015.

3. Australian Orthopaedic Association National Joint Replacement Registry. Annual Report 2013. Available at: https://aoanjrr.dmac. adelaide.edu.au/en/annual-reports-2013. Accessed June 11, 2015.

4. Blakey CM, Eswaramoorthy VK, Hamilton LC, Biant LC, Field RE. Mid-term results of the modular ANCA-Fit femoral component in total hip replacement. $J$ Bone Joint Surg $B r$. 2009;91:1561-1565.

5. Botti TP, Gent J, Martell JM, Manning DW. Trunion fracture of a fully porous-coated femoral stem: case report. J Arthroplasty. 2005;20:943-945.

6. Charles MN, Bourne RB, Davey JR, Greenwald AS, Morrey BF, Rorabeck CH. Soft-tissue balancing of the hip: the role of femoral offset restoration. Instr Course Lect. 2005;54:131-141.

7. Dangles CJ, Altstetter CJ. Failure of the modular neck in a total hip arthroplasty. J Arthroplasty. 2010;25:1169.e5-7.

8. Doehring TC, Rubash HE, Dore DE. Micromotion measurements with hip center and modular neck length alterations. Clin Orthop Relat Res. 1999;362:230-239.

9. Dorn U, Neumann D, Frank M. Corrosion behavior of tantalumcoated cobalt-chromium modular necks compared to titanium modular necks in a simulator test. J Arthroplasty. 2014;29:831835.

10. Duwelius PJ, Burkhart B, Carnahan C, Branam G, Ko LM, Wu Y, Froemke C, Wang L, Grunkemeier G. Modular versus nonmodular neck femoral implants in primary total hip arthroplasty: which is better? Clin Orthop Relat Res. 2014;472:1240-1245.

11. Ellman MB, Levine BR. Fracture of the modular femoral neck component in total hip arthroplasty. J Arthroplasty. 2013; 28:196.e1-5.

12. Enoksen CH, Gjerdet NR, Klaksvik J, Arthursson AJ, SchnellHusby O, Wik TS. Initial stability of an uncemented femoral stem with modular necks: an experimental study in human cadaver femurs. Clin Biomech (Bristol, Avon). 2014;29:330-335.

13. Garg B, Mittal R, Rastogi S. Femoral prosthesis neck fracture following total hip arthroplasty: a case report. Acta Orthop Belg. 2011;77:406-409.

14. Georgiou C, Evangelou K, Theodorou E, Provatidis C, Megas P. Does choice of head size and neck geometry affect stem migration in modular large-diameter metal-on-metal total hip arthroplasty? A preliminary analysis. Open Orthop J. 2012;6: 593-600.

15. Gill IP, Webb J, Sloan K, Beaver RJ. Corrosion at the neck-stem junction as a cause of metal ion release and pseudotumour formation. J Bone Joint Surg Br. 2012;94:895-900.

16. Grupp TM, Weik T, Bloemer W, Knaebel HP. Modular titanium alloy neck adapter failures in hip replacement: failure mode analysis and influence of implant material. BMC Musculoskelet Disord. 2010;11:3.

17. Jauch SY, Huber G, Haschke H, Sellenschloh K, Morlock MM. Design parameters and the material coupling are decisive for the micromotion magnitude at the stem-neck interface of bi-modular hip implants. Med Eng Phys. 2014;36:300-307.
18. Jauch SY, Huber G, Sellenschloh K, Haschke H, Baxmann M, Grupp TM, Morlock MM. Micromotions at the taper interface between stem and neck adapter of a bimodular hip prosthesis during activities of daily living. J Orthop Res. 2013;31:11651171.

19. Matsushita A, Nakashima Y, Fujii M, Sato T, Iwamoto $Y$. Modular necks improve the range of hip motion in cases with excessively anteverted or retroverted femurs in THA. Clin Orthop Relat Res. 2010;468:3342-3347.

20. McGrory BJ, Morrey BF, Cahalan TD, An KN, Cabanela ME. Effect of femoral offset on range of motion and abductor muscle strength after total hip arthroplasty. J Bone Joint Surg Br. 1995;77:865-869.

21. Menciere ML, Amouyel T, Taviaux J, Bayle M, Laterza C, Mertl P. Fracture of the cobalt-chromium modular femoral neck component in total hip arthroplasty. Orthop Traumatol Surg Res. 2014;100:565-568.

22. Omlor GW, Ullrich H, Krahmer K, Jung A, Aldinger G, Aldinger P. A stature-specific concept for uncemented, primary total hip arthroplasty. Acta Orthop. 2010;81:126-133.

23. Sakai T, Ohzono K, Nishii T, Miki H, Takao M, Sugano N. A modular femoral neck and head system works well in cementless total hip replacement for patients with developmental dysplasia of the hip. J Bone Joint Surg Br. 2010;92:770-776.

24. Sakalkale DP, Sharkey PF, Eng K, Hozack WJ, Rothman RH. Effect of femoral component offset on polyethylene wear in total hip arthroplasty. Clin Orthop Relat Res. 2001;388:125-134.

25. Schmidutz F, Beirer M, Weber P, Mazoochian F, Fottner A, Jansson V. Biomechanical reconstruction of the hip: comparison between modular short-stem hip arthroplasty and conventional total hip arthroplasty. Int Orthop. 2012;36:1341-1347.

26. Silverton CD, Jacobs JJ, Devitt JW, Cooper HJ. Midterm results of a femoral stem with a modular neck design: clinical outcomes and metal ion analysis. J Arthroplasty. 2014;29:1768-1773.

27. Skendzel JG, Blaha JD, Urquhart AG. Total hip arthroplasty modular neck failure. J Arthroplasty. 2011;26:338.e1-4.

28. Sotereanos NG, Sauber TJ, Tupis TT. Modular femoral neck fracture after primary total hip arthroplasty. J Arthroplasty. 2013;28:196.e7-9.

29. U.S. Food and Drug Administration. MAUDE - Manufacturer and User Facility Device Experience. Available at: http://www. accessdata.fda.gov/scripts/cdrh/cfdocs/cfmaude/search.cfm. Accessed July 1, 2015.

30. Viceconti M, Baleani M, Squarzoni S, Toni A. Fretting wear in a modular neck hip prosthesis. J Biomed Mater Res. 1997;35:207216.

31. Viceconti M, Ruggeri O, Toni A, Giunti A. Design-related fretting wear in modular neck hip prosthesis. J Biomed Mater Res. 1996;30:181-186.

32. Wodecki P, Sabbah D, Kermarrec G, Semaan I. New type of hip arthroplasty failure related to modular femoral components: breakage at the neck-stem junction. Orthop Traumatol Surg Res. 2013;99:741-744.

33. Wright G, Sporer S, Urban R, Jacobs J. Fracture of a modular femoral neck after total hip arthroplasty: a case report. $J$ Bone Joint Surg Am. 2010;92:1518-1521. 